\title{
Los colgantes renacentistas
}

\author{
Natalia Horcajo Palomero *
}

\section{RESUMEN ABSTRACT}

La joyería europea del siglo XVI es una disciplina muy compleja por el número de piezas que han llegado hasta nosotros, $y$ porque muchas de ellas tienen un tema representado en su parte central. De todos los tipos de joyas, en este trabajo se analiza el denominado joyel o colgante renacentista, un colgante de forma cruciforme, en oro esmaltado trabajado con motivos decorativos del Renacimiento y decorado con piedras preciosas engarzadas entre ellos. Presenta tres tipos, el más sencillo, que le da nombre, el que tiene un tema desarrollado entre los motivos y el que muestra una hornacina con figuras en su parte central. Su análisis en cuanto ejemplares, su localización en diseños, documentos y retratos, constituye el argumento de este artículo.
The Renaissance jewellery is very complete. We know a lot of jewels of different types and there are very much themes on them. Between the types, in this anticle we study the denominated joyel or Renaissance pendent, a cruciform pendent in enameled gold with Renaissance decorative motives, with precious stones linked on them. This pendent presents hree types. The most symple, one that has some theme on it and, a third wich has a niche with figures. The study of these jewels and their localization on designs, documents and portraits, is the end of this work.

La Joyería Europea del siglo XVI es una de las manifestaciones artísticas más complejas que existen,debido a la variedad de tipos de joyas que presenta y al altísimo número de temas en ellos representados.

Quizás de todos los tipos uno de los más relevantes sea el denominado joyel o colgante renacentista, por los elementos decorativos del

* Doctora en Historia del Arte. UCM. 
Renacimiento que muestra: Grutescos, guirnaldas de frutas, putti, roleos, bucraneos, cartelas recortadas, mascarones, motivos «a candelieri»... Este tipo genérico presenta tres variantes, la primera y más elemental, que da nombre a la joya, la segunda, el colgante que tiene añadido un tema en su parte central, y la tercera, aquel que tiene una hornacina o nicho con personajes y por lo tanto, también un tema determinado.

Los tres tipos constituyen joyas de gran belleza,de las que han llegado hasta nosotros múltiples ejemplos, pero además su presencia puede ser igualmente localizada en dibujos o grabados realizados para su ejecución,en documentos de la época y en retratos de personajes del entorno europeo del siglo XVI.

En los tres, la estructura base es la misma: Un formato cruciforme de bordes recortados, en el que en oro esmaltado de negro, blanco, rojo, verde, azul..., se realizan todos los elementos decorativos citados anteriormente, con tres cadenas o una doble anilla en el ápice para la suspensión, y una o tres anillas en la base para colgar de ellas, la mayoría de las veces, perlas en forma de pera.

En el primer tipo, el llamado joyel o colgante renacentista propiamente dicho, entre los elementos renacentistas se aprecian monturas poligonales, piramidales o lobuladas, engastadas con piedras preciosas talladas en tabla, siempre dispuestas de forma simétrica y generalmente en número par.

En el segundo tipo, que se podría denominar joyel o colgante renacentista figurado, un grupo de pequeñas figuras en bulto redondo, dos o más, aparecen en el centro o parte superior de la composición, representando un tema muy concreto y variado, religioso, alegórico, mitológico etc... En ocasiones el lugar de las figuras es ocupado por unas iniciales de simbolismo profano o religioso.

El tercer tipo es una variedad del segundo, consistente en que esas figurillas aparecen situadas en una hornacina o nicho a veces decorado con una venera como es típico que así suceda en el Renacimiento.

Este modelo de joya no es específico de un país concreto, ya que su rastro puede ser localizado en todas las naciones europeas con talleres de joyería importantes, aunque este es el momento de señalar que las joyas eran consideradas como artículos muy por debajo de otras actividades artísticas relacionadas con el trabajo en metales preciosos, y sus realizadores preferían ser denominados orfebres antes que «joyeros», como ponen de manifiesto los documentos consultados.

Debía de ser una joya muy apreciada por la cantidad de ejemplares que han sobrevivido y de algunos de ellos, los más interesantes se comentará seguidamente. 


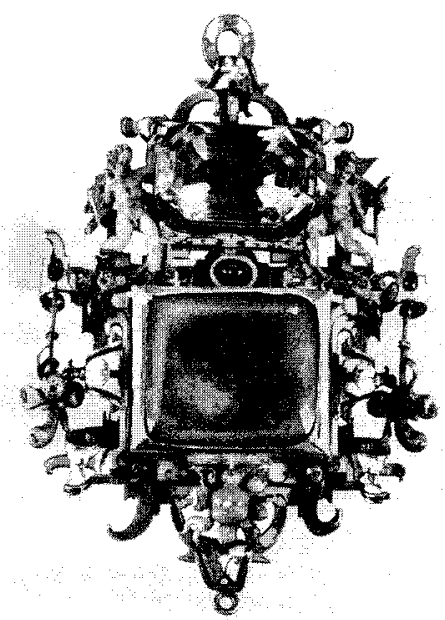

Fig. 1. Joyel o colgante renacentista. Alemania, 1566. Schatzkammer der Residenz, Munich.

El país originario de este tipo de joyas parece ser Alemania, por las numerosas piezas que tiene atribuidas, y porque en Alemania y más concretamente en Augsburgo y Nuremberg, estaban dos de los centros más importantes de la joyería europea del siglo XVI, y se encuentran ejemplares a lo largo de todo el siglo, aunque los más bellos corresponden a la segunda mitad, cuando el "manierismo" ya se había hecho realidad en algo tan exquisito como es una joya.

Del primer tipo de joyas que nos ocupa, treinta son los ejemplares que han sido localizados, la mayoría de procedencia alemana, y en el caso concreto de uno de ellos, realizado en oro esmaltado, con un aguamarina y una piedra roja engastadas, la primera con talla octogonal y la segunda rectangular tabla, (Fig. 1), Watzdorf señala que fue un regalo de los Fugger a Alberto $V$ de Baviera en 1566, según se desprende del contenido de unas cartas intercambiadas entre el Duque y los Banqueros, entre 1565 y 1579. Watzdorf añade algo inusual, el nombre de los tres orfebres de Augsburgo que al parecer realizaron la pieza, Dionys Müller, Stephan Fröschl y Hans Duecher, maestros de los que no se dispone de ningún otro dato y que no figuran en las lista de los «joyeros» más populares y mencionados de la época ${ }^{1}$.

WATDORF, ERNA V.: "Mielich und die Bayerischen goldschmiederwerke der Renaissance». Münchener Jahrbuch der Bildenken Kunst. no XII (1937), pág. 74. 


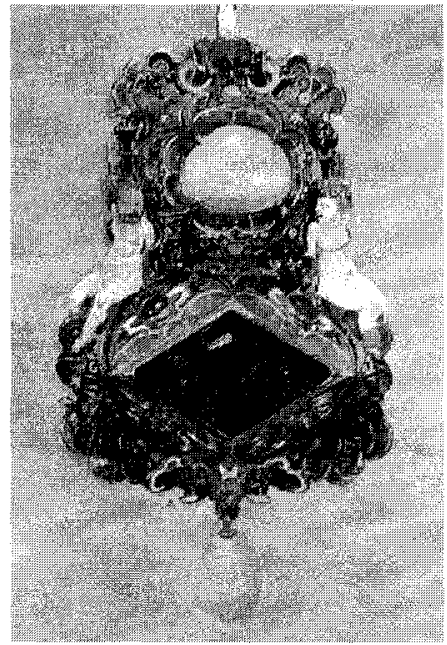

Fig. 2. Joyel o colgante renacentista. Alemania, hacia 1550-1560. The Antique Porcelain Company, Nueva York.

Los demás colgantes son anónimos, aunque de otro en oro esmaltado, con una piedra roja cuadrada tabla y una perla redonda pinjante, en el Kunstgewerbemuseum de Berlín, del que se carece de reproducción fotográfica, según Kühnel-Kunze, ${ }^{2}$ está inspirado en un diseño del al parecer alemán Hans Brosamer, quien nació aproximadamente en 1480 y murió hacía 1550. Fue grabador de diseños destinados a la joyería y su obra recibe el título de «Kunstbüchlein»y «New Kunstbüchlein Von Mancherly Echönem Trinckgeschirren", este último trabajo publicado en Nuremberg entre 1545 y $1548{ }^{3}$.

Otros, dos colgantes alemanes de la segunda mitad del siglo XVI, en oro esmaltado con cartelas recortadas, uno con un ópalo oval cabujón engastado, sobre un rubí trapezoidal tabla, con dos figurillas flanqueando las piedras y una perla pera pinjante, el otro con dos piedras engarzadas, la

2 KÜHNEL-KUNZE, IRENE: «Hans Brosamer und the meister HB mit dem greifenckopf (Ein weiterer Beitrag zur Brosamer-F'orschung)". Zeitschrrift des Deutschen Verenis für Kunst-Wissenschaft. nº XIV (1960), págs. 58-59.

3 Clifford SMith, H.: Jewellery, Londres, Ep. Publishing Limited, 1973, pág. 193; GutLmARD, Desirée.: L'Art de l'Ornamentation des Maîtres Ornementistes. París, E. Plon et Cie. Imprimeurs Editeur, 1880, pág. 365; STEINGRÄBER, Erich.: Antique jewellery:Its History in Europe from 800 to 1900. Londres, Thames \& Hudson, 1957, págs. 98-99; HAYwARD, J. F.: Virtuoso goldsmiths and the triumph of Mannerist. 1540-1620. Londres, Sotheby Parke Bernet, 1976, págs. 73 y 99; Hackenbroch, Yvonne: Renaissance Jewellery. Londres, Sotheby Parke Bernet, 1979, pág. 123. 
superior cabujón y la inferior hexagonal y una perla pera pinjante bajo una cabecita de niño (Figs. 2 y 3), son relacionados con el inventario, «Das Kleinodienbusch", que el pintor Hans Mielich realizó para los Duques de Baviera. El Duque Alberto V fundó el Schatzkammer de Munich en 1565 y el pintor recibió la orden de pintar sobre pergamino las joyas de la familia, aunque también es posible que llegase a realizar, como piensan algunos estudiosos, diseños para joyas ya que parece ser que influyó en los «joyeros» de su época. Mielich nació en Alemania hacia 1515 o 1516, y murió en 15734.

Todos los ejemplos citados son de la segunda mitad del siglo XVI, y también de este momento, $y$ de entre las demás piezas atribuidas a otros países, cabe destacar un colgante francés, en oro esmaltado con dos esmeraldas superpuestas, triangular y rectangular tablas, flanqueadas por dos diamantes trapezoidales envueltos en cartelas con dos volutas con una cabecita femenina encima, un putto a cada lado y debajo dos manos

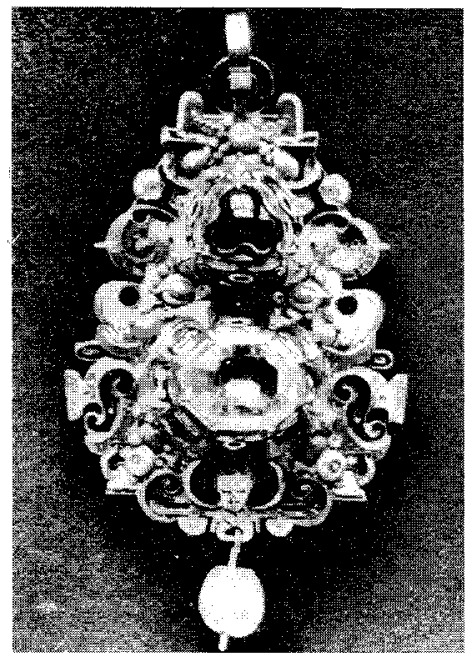

Fig. 3. Joyel o colgante renacentista.Alemania, hacia 1560. Historisches Museum der Stadt, Colonia.

4 Clifford SMith, H.: Op. cit., págs. 194-195; HAYward, J.F. Virtuoso Goldsmiths..., pág. 737; Steingräber, E: Op. cit., pág. 110; GreorietTI, Guido: Le monde merveilleuse des bijoux. París, Editions des Deux Cogs d'Or, 1973, pág. 201; Evans; JOAN, A History of Jewellery, 1100-1870. Londres, Faber \& Faber, 1970, pág. 97; TAIT, HUGH.: Historiated Tudor jewellery. The Antiquaries Journal, $n^{0}$ XLII (1962), págs. 243-244; HACKENBROCH, Y.: Renaissance..., pág. 128; HACKENBROCH, $Y .:$ «New Knowledge on jewel and design after Etienne Delaune». The Connoisseur, $\mathrm{n}^{\circ} 162$ (1966), pág. 87; HACKENBROCH, Y.: «Jewellery of the Court of Albrecht $V$ at Munich». The Connoisseur, $n^{\circ}$ 165 (1967), pág. 74. 
enlazadas (fig. 4), que para Hackenbroch fue realizado por orden de Catalina de Médicis por el orfebre François Dujardin, del que se conoce que trabajó para la reina en varias ocasiones y que en 1570 llegó a ser orfebre y lapidario del rey, muriendo en París cinco años después ${ }^{5}$.

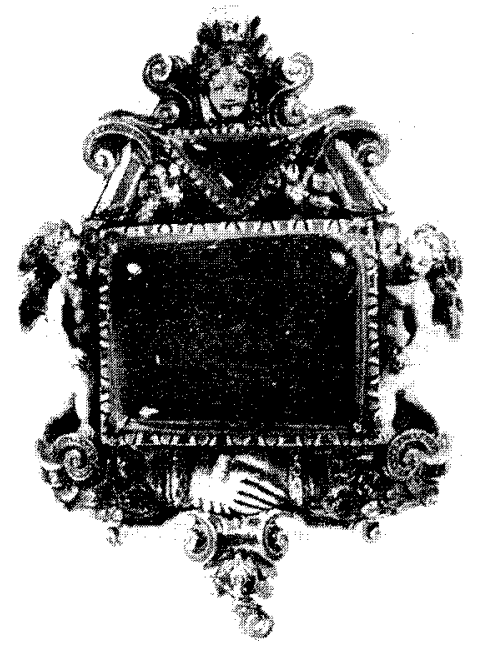

Fig. 4. Joyel o colgante renacentista. Francia, 1571. Cabinet des Médailles, Bibliothéque Nationale, París.

Hay un colgante renacentista con un valor muy peculiar, se trata de un talismán conservado en el Museo Victoria \& Alberto de Londres que fué estudiado por Evans en $1926^{6}$, y que siguiendo el tipo que nos ocupa, es de oro esmaltado, aunque le queden pocos restos de esmaltes y lleva engarzados un peridoto y un jacinto, con un zafiro en forma de lágrima pinjante. Según Evans formaba parte de la colección Cook y se vendió en Londres en 1929 como un colgante español del siglo XVI, aunque lo considera trabajo inglés de hacia 1540 , relacionándolo con los diseños para joyas del pintor Hans Holbein y considerando la posibilidad de que la hubiese realizado un amigo suyo, el orfebre John Anwarpe o Juan de Amberes, establecido en Londres quizás ya en 1511 ó 1513 donde trabajó para la reina María Tudor. Sin embargo, la talla de las dos piedras engastadas, rectangular y hexagonal con varias facetas, lleva a pensar en

5 HaCKENBROCH, Y.: Renaissance..., págs. 93-94; HACKENBROCH, Y.: «Catherine de Medici and her court jeweller Françoise Dujardin». The Connoisseur, nํ 163 (1966), págs. 28 y ss.

${ }^{6}$ Evans, Joan.: «Un bijou magique dessiné par Hans Holbein». Gazette des Beaux Arts., $\mathrm{n}^{\circ}$ XIV, (1926), págs. 357 y ss. 
una segunda mitad o mejor fines del siglo XVI, aunque sobre su origen inglés, como ya se ha expuesto y como se verá más adelante no parece que pueda haber discusión. Hasta aquí el colgante no presenta nada que haga sospechar de su uso como talismán, pero el reverso resuelve las dudas a través de dos inscripciones. La superior que rodea al peridoto reza: $A N$ NANIZAPTA + DEl, y la segunda, rodeando el jacinto dice: DETRAGRAMMATA + IHS + MARIA. Esta última inscripción carece de complejidad, aunque tiene un error ortográfico, en lugar de DETRAGRAMMATA debería de poner TETRAGRAMMATA, que significa lo Inefable, la substancia del Creador, según afirma el filósofo renacentista Agrippa ? Hay por lo tanto una mención al Padre, al Hijo y a la Madre, María. La primera inscripción, sin embargo, es más difícil.Para Evans, hace alusión a un encantamiento contra !a muerte recogido por Reginald Scot en su «Discovery of Witchcraft» de 1584 que decía:

«Ananizapta ferit mortem, dum laere quaerit, est mala mors capta, dum dicitur Ananizapta, Ananizapta Dei nunc miserere mei" (Ananizapta llega la muerte mientras busca hacer daño, es considerada una mala muerte hasta que se dice Ananizapta, Ananizapta dioses compadeceros de mí).

Estas fórmulas mágicas habrían servido para dar al colgante todo su valor talismánico, pero las piedras preciosas también tenían propiedades mágicas y las de este colgante fueron sin duda elegidas cuidadosamente por ellas.Para Evans el peridoto, como todas las piedras de color verde, era considerada un berilo y de él se pensaba que confería alegría, velaba por el amor entre los esposos, evitaba las pesadillas, curaba las afecciones de la garganta y la boca y los desórdenes que provenían de la cabeza, protegiendo contra las enfermedades.

De todas las propiedades que se han mencionado, y teniendo en cuenta el significado de las fórmulas mágicas, sin lugar a dudas la última de ellas, la de proteger contra las enfermedades es la que encaja en este colgante, con el que se pretendía rehuir la muerte por todos los medios y si fallaba quedaba el jacinto que era considerada la piedra de los viajeros ya que les amparaba y proporcionaba buen hospedaje, lo que podría aplicarse a la muerte interpretada como el último viaje y al más Allá, la posada definitiva, de manera que siempre quedaba la posibilidad de la ayuda del jacinto, que además simbolizaba la Ascensión de Cristo a los cielos, lo que daba por hecho la Resurrección y en definitiva la Vida Eterna. Como

Agrippa, Cornelio: Filosofía oculta. Buenos Aires, Ed. Kier, S.A., 1982, Libro III, cap. XI, pág. 276. 
ninguna de las propiedades del zafiro viene al caso, cabe pensar que tal vez haya tenido un significado que se ha perdido, o que reemplaza a la piedra original que se hubiese extraviado, y que por el tipo de colgante tenía muchas posibilidades de ser una perla, que servía contra las enfermedades cardiacas y curaba el tabardillo y la peste ${ }^{3}$.

En cuanto grabados y dibujos de diseños destinados a la ejecución de joyeles o colgantes renacentistas han sido localizados ciento veintiseis, la mayoría de ellos españoles, pertenecientes a la prueba de Maestría que para ingresar en el Gremio de Orfebres tenían que realizar los orfebres catalanes y que se conservan en los llamados "Llibres de Passantíes» del Museo de Historia de la Ciudad de Barcelona.Mas lo cierto es que lo único que se conoce de estos diseñadores y futuros maestros es exclusivamente su nombre y en alguno de ellos poco más, como que han tenido que volverse a examinar por llevar tiempo fuera de la ciudad y haber perdido sus derechos. De los otros países, Francia es la que más número de diseños de este tipo tiene, seguida de Alemania, Gran Bretaña y Los Países Bajos. Esto se debe a que en Francia no solo trabajaron diseñadores franceses, como fue Etienne Delaune, sino también alemanes como Virgil Solis. Algunos de estos diseñadores eran solo grabadores, de otros, como en el caso de Delaune se sabe que también eran orfebres.

De todos los diseñadores franceses el ya citado Etienne Delaune puede ser considerado sin duda el más interesante. También llamado Stephanus, probablemente nació en Orleans en 1518 y es posible que fuese uno de los orfebres que trabajó con Cellini en París. En 1552 era el Orfebre y Grabador Real de Enrique II y en 1572 quizás por problemas religiosos relacionados con la Noche de San Bartolomé, marchó a Estrasburgo de donde pasó a Augsburgo, donde tuvo su propio taller, para regresar de nuevo a Estrasburgo y morir en París en la década de los ochenta ${ }^{\circ}$. Su obra grabada comprende 443 láminas fechadas en 1561, 1573 y 1576. De ella puede destacarse entre varios, un diseño para un colgante de este tipo, formado por cartelas recortadas y enrolladas entremezcladas con racimos de frutas, con dos piedras engastadas en monturas polilobuladas, la superior rectangular tabla y la inferior, de mayor tamaño, cabujón. Completan el diseño dos figuras de sátiros y dos máscaras, una arriba, bajo la anilla de suspensión, la otra debajo, sobre una perla pera pinjante (Fig.5).

\footnotetext{
Morales, Gaspar DE: De las virtudes y propiedades maravillosas de las piedras preciosas. Madrid, Editora Nacional, 1977, págs. 262 y ss.

HoRcajo Palomero, Natalia: «Sobre dos diseños europeos de joyas grabados en el siglo XVI y su posible influencia en las pruebas de maestría de dos orfebres catalanes». Archivo Español de Arte, n² 264 (1993), págs. 414-415.
} 


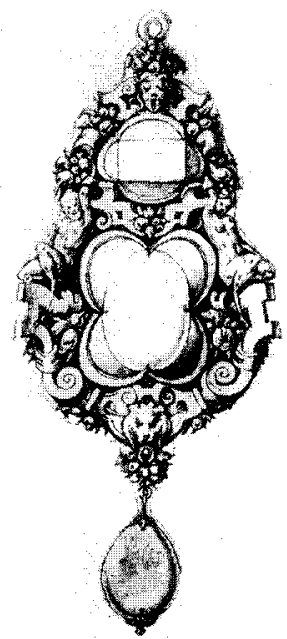

Fig. 5. Diseño grabado para un colgante renacentista.Etienne Delaune, Francia, 1561. Ashmoleam Museum, Oxford.

Los documentos consultados también recogen numerosa información sobre el joyel o colgante renacentista. En España aparecen inventariados en todas las partidas de joyas de la familia real, y por poner un ejemplo, se puede citar el siguiente:

"Un diamante tabla grande $n^{\circ} 30$ tabla con una perla por pinjante pendiente engastado en unas piezas de oro grande labrado de frutales y esmaltado de diversos colores tasose en treinta y mil ducados».

Este joyel más adelante se especifica que siendo propiedad de Isabel de Valois, tercera esposa de Felipe II, le fue dado, a su muerte, a su hija Catalina Micaela ${ }^{10}$.

De los retratos y por la belleza de todo el conjunto, es conveniente señalar el de la Infanta Isabel Clara Eugenia y Magdalena Ruiz, de hacia 1585-1588, obra del pintor Alonso Sánchez Coello, que se conserva en el Museo del Prado de Madrid, (fig. 6). La Infanta, sobre el pecho y suspendido de un pesado collar, de diseño similar al colgante, lleva un joyel de este tipo, en oro con roleos y cartelas recortadas y enrolladas, esmaltado

10 "Archivo General de Simancas" (AGS). Casa y Sitios Reales, legajo 67, Folio 2, p. IV. 12 de Agosto de 1569. «Inventario de los bienes muebles de la Reina $\mathrm{D}^{\mathrm{a}}$ Isabel de los que se encargó Cristobal de Oviedo por orden de Antonio de la Cueva". 


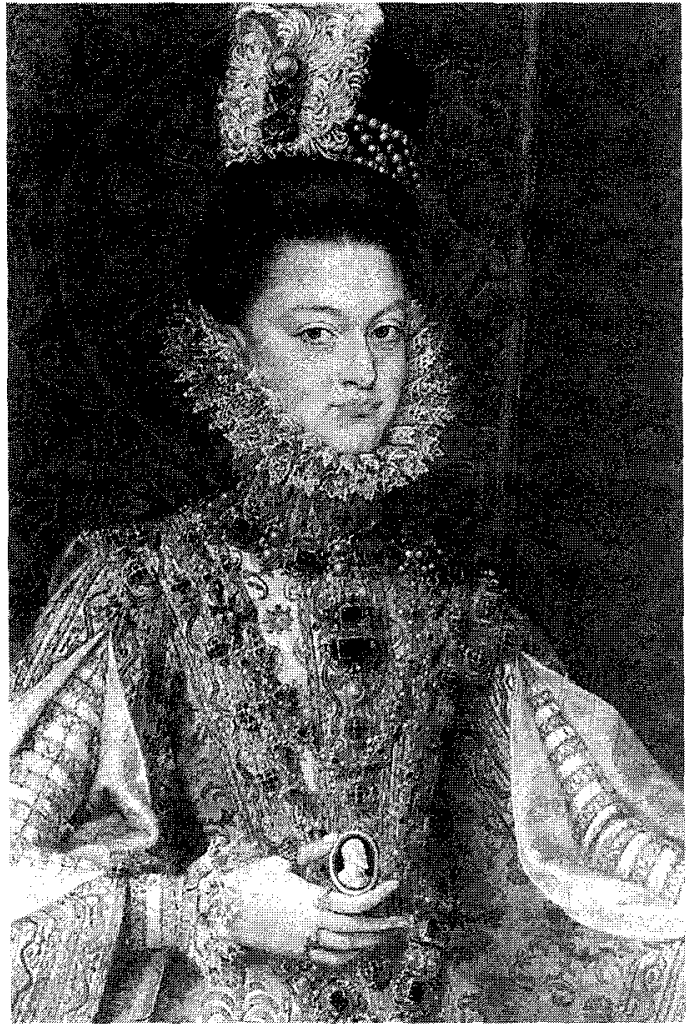

Fig. 6. Retrato de Isabel Clara Eugenia y Magdalena Ruiz (detalle). Alonso Sánchez Coello, hacia 1584-1588. Museo del Prado, Madrid.

fundamentalmente en negro y engastado con dos piedras ¿diamantes? con talla tabla, la superior cuadrangular, y la inferior más grande, rectangular.Colgando en la base, una perla redonda pinjante.

Del segundo tipo de joyel o colgante renacentista, aquel que mostraba una escena central representada por pequeñas figurillas han sobrevivido o se conocen noventa ejemplares y es también en Alemania donde se registran el mayor número de piezas, en esta ocasión seguida de lejos por Italia. Los temas representados en ellos no pueden ser más variados: Religiosos, alegóricos, mitológicos, zoológicos... Alemán y de fines del siglo XVI, es un bello ejemplo de este tipo de colgantes en el British Museum de Londres. Con tema mitológico presenta en su parte central la figura de Venus sobre una concha sostenida por dos delfines, destacados sobre un fondo de roleos calados y esmaltados, con dia- 
mantes, rubíes, perlas y un zafiro engastados entre ellos, en monturas piramidales, con tres perlas redondas pinjantes en la base, la central algo mayor de tamaño. Otro, igualmente de tema mitológico, italiano y perteneciente al tesoro del Gran Duque de Toscana, presenta una escena de amores de dioses: Sobre un fondo de roleos calados en oro esmaltado de diversos colores con diamantes, rubíes, esmeraldas y perlas engastadas, destaca la pareja de dioses en bulto redondo y oro esmaltado, están semidesnudos y en actitud amorosa. El colgante se suspende por tres cadenas a una anilla, y en el bajo lleva tres perlas peras pinjantes. Es considerado trabajo de fines del siglo XVI y se conserva en el Museo degli Argenti del Palacio Pitti de Florencia, (fig. 7).

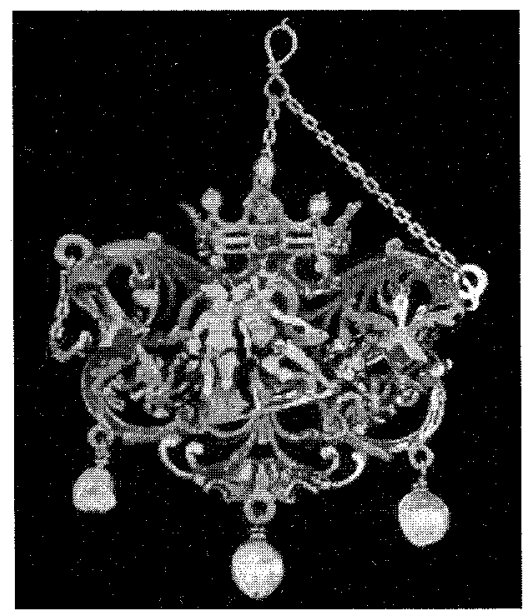

Fig. 7. Joyel o colgante renacentista figurado con tema mitológico: Los amores de los dioses. Italia, fines del siglo XVI. Museo degli Argenti, Palacio Pitti, Florencia.

De los diseños localizados, veinticinco, la mayoría son de procedencia alemana y francesa, los alemanes realizados a lo largo de todo el siglo XVI, los franceses de la segunda mitad.Sin embargo, se ha elegido a un diseñador de los Países Bajos para comentar una de sus obras, demostrándose con ello ese carácter tan europeo que se ha señalado para este tipo de colgantes.Se trata de Hans Collaert quien pertenecía a una familia de grabadores, nacido en Amberes en 1530 y muerto en 1581, año en que a título póstumo se editó su serie de grabados: «Monilium Bullarum In Aurumque Artificiossimae Iconis.Joannis Collaert opus postremum, 1581». De las estampas se ha elegido una para un colgante renacentista figurado con tema mitológico: Zeus. En la composición general no faltan los motivos renacentistas ya señalados, entre ellos y en el centro, aparece la figura del dios 
griego sobre su águila con el rayo amenazador en su mano. Flanqueando la figura de Zeus hay dos figuras femeninas desnudas sentadas, posiblemente también diosas aunque difíciles de identificar. Completan el colgante tres perlas peras pinjantes.

De su presencia en documentos, en un inventario de las joyas de la corona de Francia de 1560 aparece:

«Ung phenix emaillé, garny d'ung grand feuillage d'or et quelques petites perles, estime $X$ " (un fénix esmaltado, guarnecido de un gran follaje de oro y ciertas perlitas, estimado en $X){ }^{11}$.

De los colgantes de este tipo representados en retratos, destaca el que suspendido sobre el hombro izquierdo luce una Dama desconocida, en una pintura atribuida a Alonso Sánchez Coello en el Museo Ermitage de Leningrado en Rusia, del que se carece de reproducción fotográfica. Se trata de un joyel que tiene en su parte superior la figura de un perro de pie, sobre roleos y cartelas enrolladas, con una piedra rectangular tabla engastada y tres perlas peras pinjantes en la base ${ }^{12}$.

Al hacer referencia a este tipo, segundo, de joyeles, se ha dicho que existe una variedad, un pequeño número de piezas, no llegan a la decena, que en lugar de unas figurillas representando un tema, tenian unas iniciales de tipo simbólico, profano o religioso. De tema profano destacan dos ejemplares alemanes de mediados del siglo XVI, relacionados con Ana de Sajonia, hija de Cristian III de Dinamarca y esposa de Augusto de Sajonia. El primero de ellos, en oro esmaltado con cartelas recortadas con flores y frutas, tiene destacadas en el centro dos « $A$ » entrelazadas, engarzadas de diamantes cuadrados talla tabla y coronadas por una diadema de rubíes igualmente cuadrados tablas y cabujones, sostenida por dos putti esmaltados en blanco.La anilla para la suspensión se apoya en un querubín, mientras que la de la base, que ha perdido la perla pinjante, lleva un mascarón encima (fig. 8). La joya es considerada un regalo de Augusto de Sajonia a su esposa Ana y para Hackenbroch, este colgante se puede relacionar con las pinturas de joyas de Hans Mielich ${ }^{13}$. El segundo, muy similar en cuanto al fondo, tiene una sola «A», engastada con diamantes cuadrados y trapezoidales tablas, flanqueada por dos pequeñas figurillas femeninas que sostienen una corona de laurel sobre ella. Bajo la letra se asoma la Fama, alada y tocando una tuba doble. La anilla para la suspensión también se

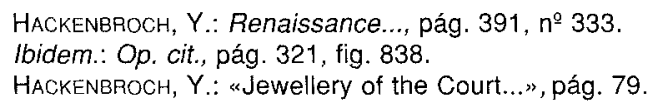




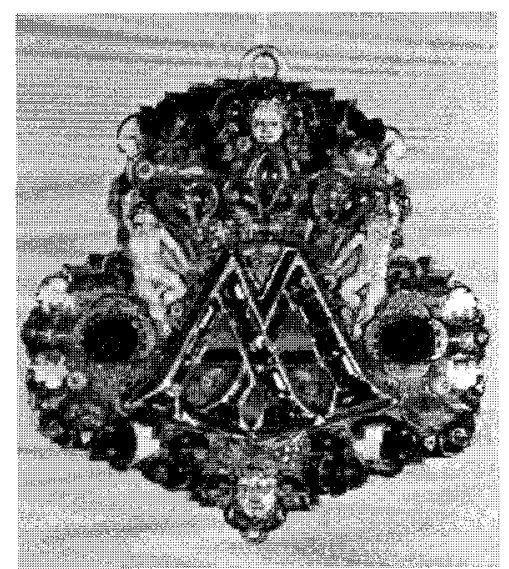

Fig. 8. Joyel o colgante renacentista con iniciales. Alemania, hacia 1560, Grünes Gewölbe, Dresde.

apoya en un querubín y la de la base ha perdido igualmente la perla (fig. 9). Aunque el colgante se relaciona con Ana de Sajonia, la presencia de la corona de laurel sobre la inicial más induce a pensar en su esposo Augusto y en una alusión a los emperadores romanos. Hackenbroch señala que el colgante tiene relación con los diseños de Etienne Delaune ${ }^{14}$.

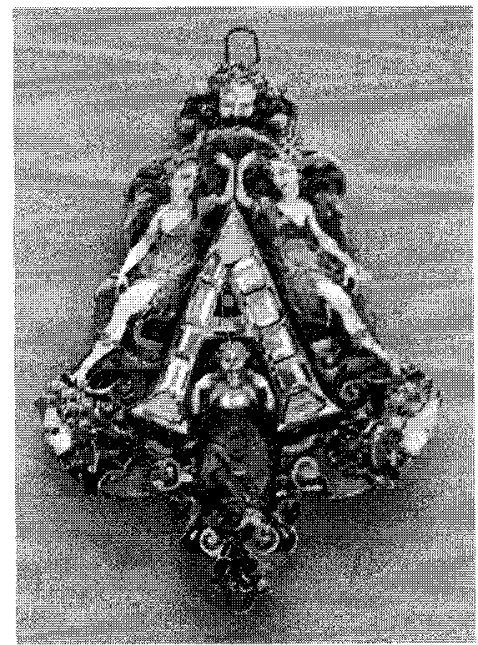

Fig. 9. Joyel o colgante renacentista con iniciales. Alemania o Francia, hacia 1560. Grünes Gewölbe, Dresde.

14 HaCKenBroch, Y.: «New knowledge on jewels...», págs. 86-87. 
Con simbolismo religioso el tema preferido es el monograma «IHS» (lesum habemus socium, tenemos a Jesús como amigo) adoptado en el siglo $\mathrm{XVI}$ por la compañía de Jesús. Aunque como joya solamente formada por las letras engarzadas con piedras, y no dentro de la variedad del llamado joyel o colgante renacentista, existen muchos ejemplos y casi todos ellos relacionados con Inglaterra, con la familia real, Enrique VIll y sus mujeres, y el pintor Hans Holbein, de este tipo solo se ha localizado un ejemplo, alemán de mediados del siglo XVI, de oro esmaltado engastado con piedras preciosas poligonales talla tabla y con la perla pinjante de la base perdida (fig. 10).

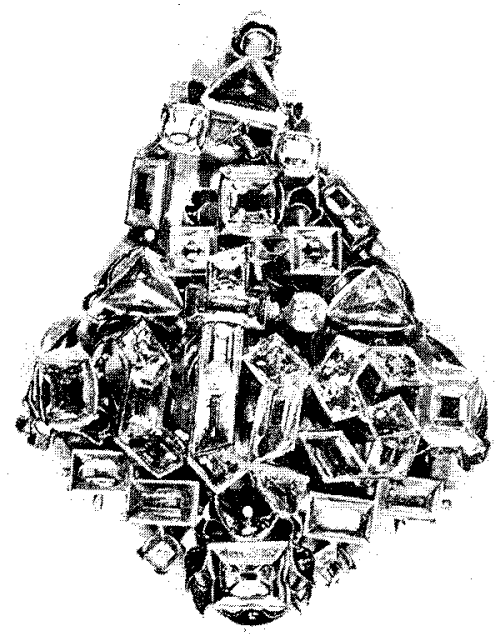

Fig. 10. Joyel o colgante renacentista con monograma. Alemania, hacia 1550 (El reverso fue renovado hacia 1600). Schatzkammer der Residenz, Munich.

Con respecto a los diseños, se han localizado solamente dos dibujos a lápiz, tinta y acuarela de dos colgantes de este tipo, trabajo de Jacob Mores, datados de hacia 1594, es decir, de fines del siglo y más cercanos al XVII, debido a la gran importancia que reciben las piedras preciosas en la composición, como será característico de ese nuevo tiempo.En cuanto a Mores, nació en Hamburgo entre 1540 y 1550, muriendo en 1612. La mayor parte de sus diseños fueron para la corte danesa, destacando el «Das Kleinodienbuch de Jacob Mores» ${ }^{15}$. Sobre los dibujos, el primero tiene encerradas en un co-

15 Steingräber, E.: Op. cit., pág. 119; Hackenbroch, Y.: Renaissance..., pág. 209 y Somers Cooks, Anne y otros.: Princely Magnificence. Court Jewels of the Renaissance, 1500-1630, Londres, Debrett's Peerage Limited in Association with Victoria \& Albert Museum, 1980, pág.128. 
razón alado y coronado, destinado a ser engarzado con diamantes y rubíes, las iniciales "G $A$ », enlazadas y sostenidas por dos manos, en clara alusión a Gustavo Adolfo y a su madre la Duquesa Cristina Zu Schleswig Holstein.Putti y otras manos, una de ellas sujetando un arco con flechas, completan la composición que tiene tres perlas peras pinjantes en la base.

El otro dibujo, más «renacentista» de diseño, presenta el monograma «IHS» destinado a ser engastado con diamantes, coronado y flanqueado por cuatro figuras, dos putti con racimos de uvas y dos figuras femeninas, una desnuda y la otra vestida, con cartelas y flores rodeando el conjunto; en la base, de nuevo las tres perlas pinjantes, en esta ocasión, la central mayor.

En los documentos españoles se han podido localizar los ejemplos que se exponen a continuación:

«El oro de un joyel de las CES de diamantes y que peso una onza quatro ochavos e un grano de veinte e dos quylates por que los diamantes los habia llevado su magestad quatro mill e quatro cientos y onze maravedis» ${ }^{16}$.

"Cargaseles mas otro joyel grande que se llama el IHUS que tiene una ese atrabesada en que estan quarenta diamantes e doze rrubies pequeños e tiene tres perlas pinjantes la una mayor que la otra y la de medio mas pequeña e de la otra parte un crucifixo y en lo alto unas ymagenes de niel que esta en el dicho joyel un ylo de perlas en una çinta blanca e unas quentas de oro redondas esmaltadas de colores de rrosycler y blanco e algunas sin esmalte que son quarenta e seis perlas e veinti e ocho quentas de oro que estaba todo junto con el dicho joyel e por lo no cortar e desconcertar de como su alteza lo tenia se peso todo junto que peso çinco onças e una ochava e quatro tomines que se hallo en las dichas arcas al tiempo que se hizo el dicho ymbentario como pareze por el dicho libro"s ${ }^{17}$.

Ninguno de los retratos consultados presenta un colgante de este tipo, aunque sí del que se ha aludido anteriormente y que no es «renacentista», por carecer de todos los elementos decorativos que le caracterizan, son

$15^{\circ}$ AGS. Patronato Real. Testamentos Reales. Caja 30, n² 119, pág. 109 v. 1551. «Inventario de las joyas, plata y recámara de la Emperatriz que el Emperador mandó repartir entre sus hijos e hijuelas".

17 AGS. Contaduría Mayor de Cuentas, Primera época. Legajo 1544, pliego 4 B. 1551-1555. «A los dichos Diego y Alonso de Ribera: Relación de las partidas que le están por descargar en su cuenta de la recámara, que pretenden que no se les debe cargar, ni han de dar cuenta de ellas, diciendo que estaban en poder de la Reina Nuestra Señora y no del dicho camarero, y que no se hallaron en el último inventario que se hizo cuando su alteza falleció, y que esto fue a causa de que disponía de ello a su voluntad, sin dar parte al escribano de cámara ni al camarero, y también por haber faltado al tiempo que la dicha reina murió, un cofre rico, donde se tenía entendido que estaban muchas joyas, de las que tenía en su cámara y las partidas son las siguientes..." y AGS. Patronato Real, caja $50, n^{\circ}$ 159.2 de Enero de $1525 \%$. Joyas recibidas por la reina de Portugal de parte del Emperador». 


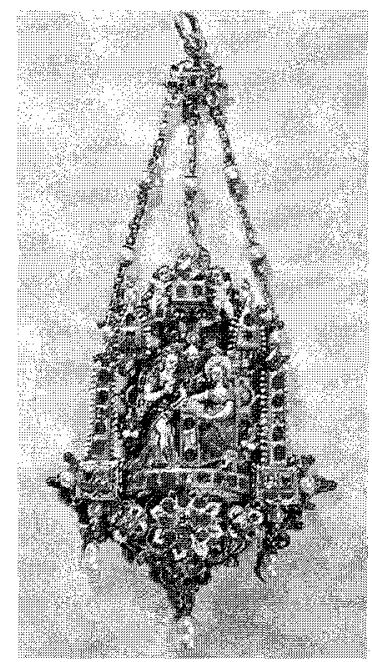

Fig. 11. Joyel o colgante renacentista con hornacina figurado con tema religioso: La Anunciación. Alemania, hacia 1570. Museo del Louvre, París.

colgantes que solo tienen las letras engastadas con piedras, a veces están suspendidos por cadenas y tienen perlas pinjantes en la base, pues no dejan de ser de la época que nos ocupa, aunque no tengan cartelas, grutescos etc..., pero estos merecen por la variedad de modelos y riqueza un estudio aparte, que ya se realizará en su momento.

Ya sólo queda por analizar el tercer tipo, sin duda el más rico e interesante, del que han sobrevivido cincuenta piezas, de las que casi la mitad están adscritas a Alemania. Los temas más representados en ellos son los religiosos, seguidos de los mitológicos y los alegóricos y luego hay algún ejemplo suelto de otros temas, como puede ser el busto de un filósofo o un pelícano. De los temas religiosos el que registra un mayor número de ejemplares es la Anunciación, por eso, una joya con este tema es la que se comentará seguidamente. Alemana, de la segunda mitad del siglo XVI es de oro esmaltado y sobre una terraza engastada con rubíes y diamantes y flanqueada por dos pilares creando una especie de hornacina, aparecen en oro esmaltado y bulto redondo el Arcangel San Gabriel en pie, saludando a María, arrodillada en un reclinatorio y en actitud de leer. Sobre ellos revolotea el Espíritu Santo como una paloma blanca, completando la composición dos angelitos. Bajo la terraza, los roleos y las formas vegetales nos recuerdan cual es el tipo de colgante que estamos contemplando.La suspensión se realiza a través de tres cadenas y en la base, las tres perlas peras de rigor, con la central algo mayor (fig. 11). 


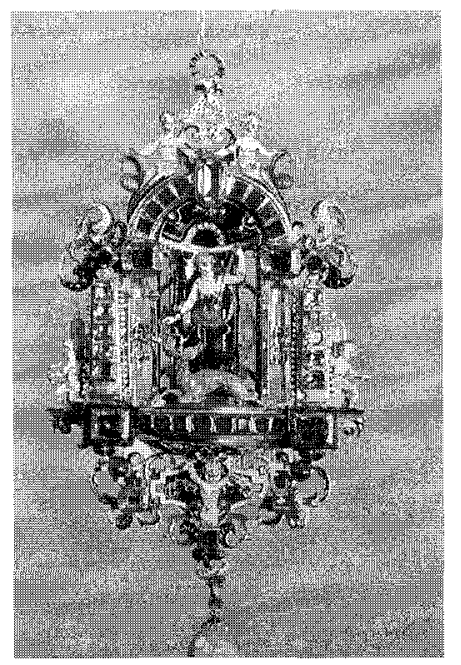

Fig. 12. Joyel o colgante renacentista con hornacina figurado con tema mitológico: Diana. Alemania o Francia, fines del siglo XVI.Colección de Mr. y Mrs. Jack Linsky, Nueva York.

De los temas mitológicos el que más aparece es el de la diosa Diana cazadora y un colgante con este tema es que se ha elegido: En oro esmaltado y sobre un fondo de cartelas recortadas, aparece un nicho tallado en jaspe sanguina apoyado sobre una terraza engastada con rubíes, flanqueado por dos pilares con diamantes y bajo un arco de medio punto de esmeraldas, todas las piedras talla tabla, con la clave del arco engarzada con un diamante rectangular facetado de gran tamaño. En el nicho, y de pie, la figura de Diana en oro esmaltado y bulto redondo, con una flecha en su mano derecha y un ciervo recostado a sus pies. Sobre el arco, hay dos putti, a cada lado de la anilla de suspensión, y hay otros dos apoyados en los pilares y disparando flechas. Bajo la terraza y entre los roleos un Hermes del que sale la anilla con la perla pera pinjante (fig. 12). Para Hackenbroch el colgante es alemán, de fines del siglo y puede estar relacionado con los diseños que Erasmus Hornick grabó durante su estancia en Augsburgo ${ }^{18}$. De este grabador se conoce que nació en Amberes hacia 1520 y que en 1540 ya estaba trabajando en Augsburgo, aunque es posible que viajase a Italia pues en sus diseños se aprecia la influencia de Giulio Romano y Francesco Salviati. En 1557 trabajó en Nuremberg para regresar a Augsburgo y pasar a Praga donde en 1582

18 HACKENBROCH, Y.: «Erasmus Hornich as a jeweller». The Connoisseur, $\mathrm{n}^{0} 166$ (1967), pág.55. 
se convirtió en Kammergoldschmed del rey Rodolfo II, muriendo allí en $1593^{19}$.

Aunque bien es cierto, y como se comentará seguidamente, que Hornick es uno de los diseñadores y posiblemente orfebre, que nos ha dejado ejemplos de este tipo de colgantes, la joya bien podría ser francesa y haber sido realizada en los talleres de la corte de Enrique II, pues el tema por un lado se relaciona con Diana de Poitiers, la amante del rey, y por otro, el nicho de sanguina verde induce a pensar en un trabajo de los seguidores del italiano Matteo dal Nassaro que trabajó en París, donde tuvo un barco con molino para tallar piedras en el Sena, y fue grabador de piedras finas y monedas del rey Francisco I.

También con Erasmus Hornick está relacionado un colgante con tema alegórico, las virtudes de la Fe, la Fortaleza y la Caridad, considerado igualmente trabajo alemán de fines del siglo XVI. En esta ocasión la hornacina tiene la parte superior cubierta por una venera y está flanqueada por dos pilastras engarzadas con diamantes y rubies tablas, con dos putti músicos

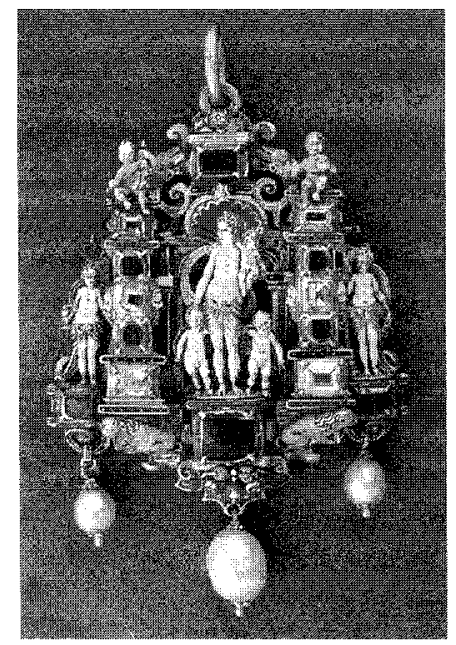

Fig. 13. Joyel o colgante renacentista con hornacina figurado con tema alegórico: Las virtudes de la Fe, la Fortaleza y la Caridad. Alemania, fines del siglo XVI. British Museum, Londres.

19 Ibidem, págs. 62-63; HACkENBROCH, Y.: Renaissance..., pág. 157; HAYWARD, J.F.: "The Mannerist Goldsmiths. 3 Antwerp. Part IV. Italian influence in the designs of Erasmus Hornick». The Connoisseur, $\mathrm{n}^{\circ} 164$ (1965), págs. 144-149; HAYWARD, J.F.: «The drawings and engraved ornament of Erasmus Hornick». The Burlington Magazine, nº CX (1968), págs. 283-289. 
encima, cobijando la figura de la Caridad, mientras que al lado de las pilastras se sitúan las otras dos virtudes. En el ápice tiene una doble anilla movible para la suspensión, y en la base, bajo una composición de roleos y mascarones, tres perlas ovales colgando, la central mayor (fig. 13).

De los diseños conocidos, diecinueve, la mayoría de los Países Bajos, por reiteradas alusiones era necesario recurrir a los que para este tipo de joyas grabó Erasmus Hornick de los que se han localizado dos, el tema de uno de ellos es religioso: Cristo Varón de Dolores, el del otro, profano, no ha sido identificado aún. En el primero, en la hornacina rodeada de roleos recortados con putti, puede verse la imagen sufriente de Cristo, asiendo la Cruz y con un caliz a sus pies, una perla pera pinjante en la base completa la composición (fig. 14). En el segundo, la hornacina con una venera, está rodeada de cartelas recortadas y enrolladas y alberga la imagen sentada en un trono y coronada de un rey que atiende a dos súbditos que pa-

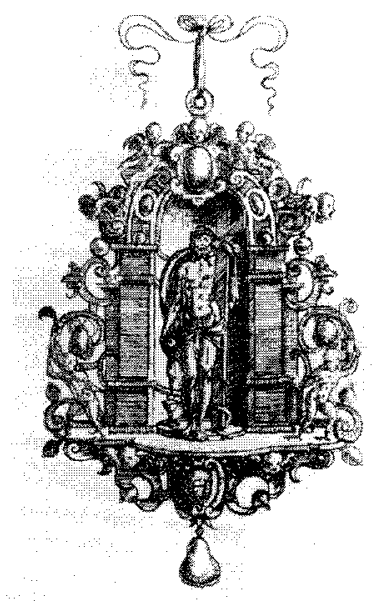

Fig. 14. Diseño grabado para un joyel o colgante renacentista con hornacina figurado con tema religioso: Cristo Varón de Dolores. Erasmus Hornick, Alemania 1565, Kunstsammlungen Veste, Coburgo.

recen esperar su respuesta ( $¿$ Ester ante Asuero acompañada de Amán o de Mardoqueo?). En la base una perla pera colgando de la montura de una piedra oval cabujón (fig. 15).

Sin embargo el mayor número de diseños grabados para este tipo de joyas que han podido ser consultados, pertenecen a Hans Collaert, hijo, se editaron en 1581 y pertenecían al «Bullarum Inaurium Etc Archetypi 


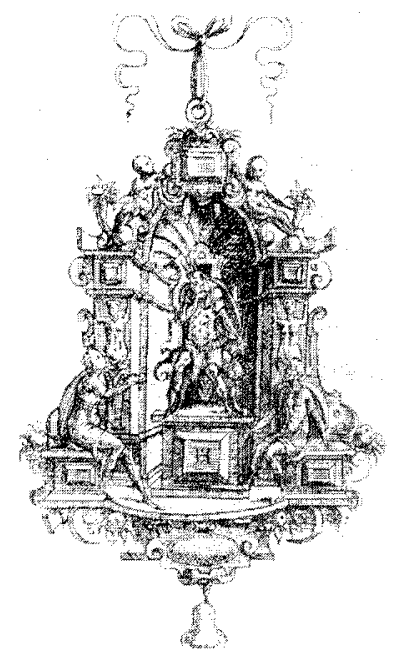

Fig. 15. Diseño grabado para un joyel o colgante renacentista con hornacina figurado con tema vario (¿Ester ante Asuero acompañada por Amán o Mardoqueo?). Erasmus Hornick, Alemania, 1565. Kunstsammlungen Veste, Coburgo.

Artificiosi» y curiosamente algunos de ellos fueron copiados por otro diseñador Adrian de Saint-Hubert, del que solo se sabe que nació en 1540 y por ei apellido se deduce que era belga o francés ${ }^{20}$. Uno de ellos presenta en la hornacina, que es una arquería abierta rodeada de mascarones, volutas, flores y frutos, la figura en pie de Diana con el cuarto de luna en la frente, y tras ella asoma una cabecita de perro.El colgante sería suspendido por una doble anilla movible en el ápice, y en la base, como siempre, tres perlas peras pinjantes, la central más grande (fig. 16).

Perteneciente a la familia Médicis los documentos recogen la siguiente pieza que bien podría tratarse de un colgante de este tipo:

«Una porta d'oro gioellata per tutto di rubini et diamanti entrovi una Fortuna con una perla pera grossa abasso" (Una puerta de oro enjoyada toda ella de rubies y diamantes, en la que se encuentra una Fortuna, con una perla gruesa abajo) ${ }^{21}$.

En los retratos, uno de los más atrayentes es el de Mrs. Ralph Sheldon, de hacia 1593-1595, obra de un artista desconocido pero perteneciente a

GuILMARD, D.: Op. cit., p. 26.

${ }^{21}$ HaCkenbroch, Y.: Renaissance..., pág. 388. 


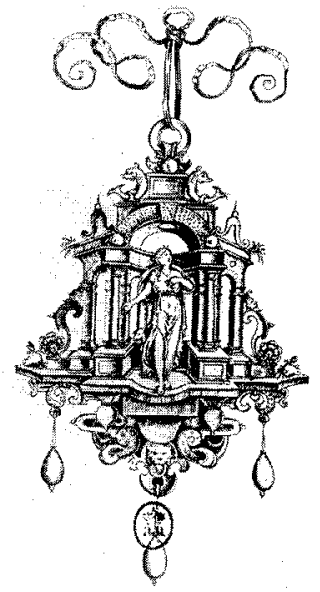

Fig. 16. Diseño grabado para un joyel o colgante renacentista con hornacina figurado con tema mitológico: Diana. Grabado por Adrian de Saint-Hubert, es una copia de una serie de Hans Collaert, El Joven, de 1582. Gabinete de Estampas, Museo dei Uffizzi, Florencia, Gabinete de Estampas, Biblioteca Nacional, Madrid y Cabinet des Estampes, Bibliothéque Nationale, París.

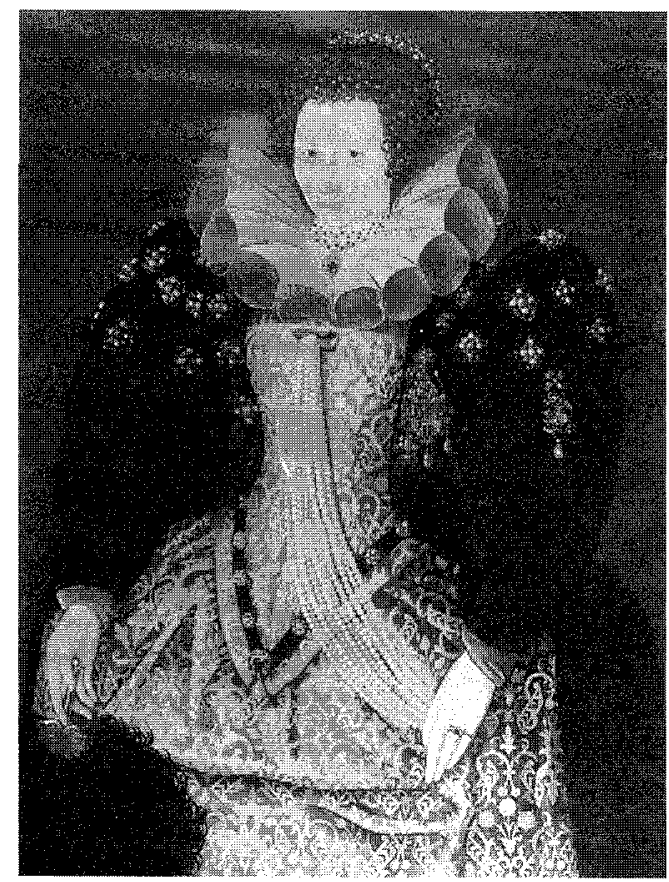

Fig. 17. Retrato de Mrs. Ralph Sheldon. Artista desconocido, Escuela inglesa, hacia 1593-1595. Colección privada. 


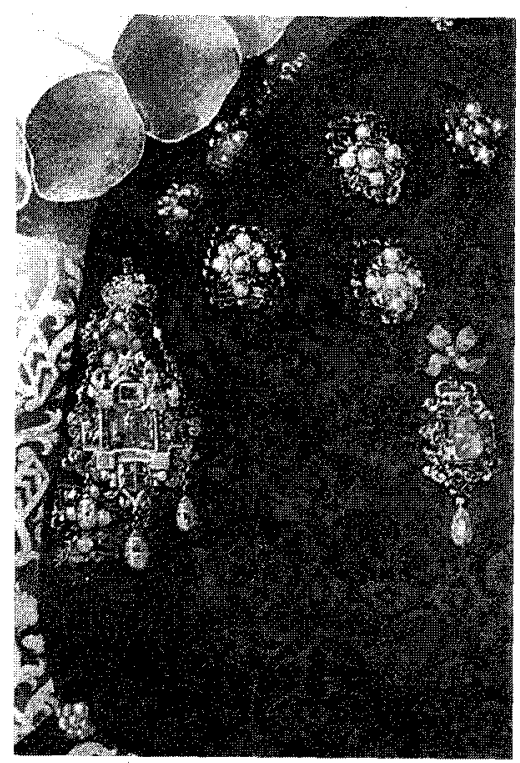

Fig. 18. Detalle del anterior.

la Escuela inglesa (figs. 17 y 18). En él, la retratada luce en su manga izquierda un colgante renacentista del primer tipo, con un gran rubí oval cabujón engastado en el centro, pero justo al lado, sobre el pecho, lleva un colgante renacentista con hornacina figurado que es un maravilla. El tema representado en él es Orfeo tocando el laúd acompañado de varios animales:Un león, un unicornio, un pájaro, un caballo y una vaca. Rodeándoles hay dos pilares engastados con diamantes tablas, dos diamantes más triangulares otro rectangular y una esmeralda, y colgando en la base parece llevar tres rubíes en forma de pera.

El estudio de todos los ejemplos que han ido apareciendo permite deducir que la Joyería del siglo XVI es una disciplina muy interesante y atrayente, de la que en este artículo se ha rozado exclusivamente una parte mínima, ya que los tipos de joyas que han llegado hasta nosotros son muchísimos, a pesar de que las joyas se deshacían y rehacían continuamente, y entre ellos los que se ha denominado joyeles o colgantes renacentistas son solo un ejemplo, pero es también una disciplina llena de dificultades por la razón que ya se ha expuesto de la poca consideración que tenían de las joyas los artistas en el siglo XVI, sin embargo el aprecio de que gozaban entre la población debía de ser mucho mayor y esto nos lo prueban los retratos con joyas, casi todos, que podemos contemplar en los museos. 